\title{
Oficinas educativas como estratégia de promoção da saúde auditiva do adolescente: estudo exploratório
}

\section{Educational workshops as a strategy to promote hearing heath of adolescents: an exploratory study}

\author{
Adriana Bender Moreira de Lacerda', Vânia Muniz Néquer Soares', Cláudia Giglio de Oliveira Goncalves', \\ Flávia Conceição Lopes², Ricardo Testoni²
}

\section{RESUMO}

Objetivo: Desenvolver e avaliar oficinas educativas sobre saúde auditiva e exposição a ruídos de adolescentes escolares da rede pública de ensino médio. Métodos: Estudo de intervenção, com a participação de 91 adolescentes. Foi realizada ação educativa, tendo como base a pedagogia problematizadora e, como recurso metodológico, o trabalho em grupo na forma de oficinas, nas quais os jovens foram convidados a refletir sobre a saúde auditiva e exposição a ruídos nas atividades culturais (lazer), escolares e ambientais. Foram utilizadas diferentes estratégias lúdicas e dialógicas, como teatro, música, roda de conversa, confecção de mural. Para avaliação das oficinas foram aplicados dois questionários: um questionário antes e outro depois das oficinas, visando identificar a mudança na compreensão dos jovens frente ao ruído, e outro sobre a dinâmica das oficinas. Resultados: Após as oficinas, foram observadas mudanças na compreensão dos jovens, que passaram a considerar o ruído como algo ruim e danoso à saúde. Diferença significativa foi observada com relação aos cuidados necessários com a audição nas atividades culturais. A percepção dos alunos relacionada à dinâmica utilizada nas oficinas foi muito boa ou boa em mais de $80 \%$ das avaliações. Conclusão: As oficinas educativas demonstraram-se apropriadas para educação em saúde auditiva de escolares. Foram observadas mudanças na compreensão dos jovens, sobretudo quanto ao efeito do ruído nas atividades culturais. As estratégias lúdicas e dialógicas propostas nas oficinas foram aceitas e apreciadas pelos adolescentes.

Descritores: Educação em saúde; Audição; Perda auditiva provocada por ruído; Serviços de saúde para estudantes; Adolescente

\begin{abstract}
Purpose: Develop and evaluate educational workshop on hearing health and noise exposure adolescents, students of public school. Methods: Intervention study involving 91 adolescents. Educational activity was conduce based on the problem-posing education and as a methodological resource group work in the form of workshops in which young people were invited to reflect on the hearing health and noise exposure in cultural activities (leisure),and environmental education. Was used differents strategies playful and dialogical as: theater, music, conversation wheel, making mural. For evaluation of the workshop were applied two questionnaires, one questionnaire before and another after the workshop aimed at identifying and understandingc an change attitudes of young people against the noise, and the other on the development of the workshop. Results: After the workshops, was observed changes in the understanding of young people, considering the noise as something bad and harmfulto health, however significant differences were observed, the necessary care with hearing related to cultural activities. The students' perceptions related to the dynamics used in the workshops was very good or goodby more than $80 \%$ of the evaluations. Conclusion: The educational workshops showed to be appropriate for health education of hearing students. Changes were observed in the understanding of teenagers, especially the effect of noise on cultural activities. The playful and dialogical strategies proposed in the workshop were accepted and appreciated by adolescents.
\end{abstract}

Keywords: Health education; Hearing; Hearing loss, Noise-induced; Student health services; Adolescent

Trabalho realizado no Programa de Pós-Graduação em Distúrbios da Comunicação, Universidade Tuiuti do Paraná - UTP - Curitiba (PR), Brasil.

(1) Programa de Pós-Graduação em Distúrbios da Comunicação, Universidade Tuiuti do Paraná - UTP - Tuiuti (PR), Brasil.

(2) Programa de Pós-Graduação (Mestrado) em Distúrbios da Comunicação, Universidade Tuiuti do Paraná - UTP - Tuiuti (PR), Brasil.

Conflito de interesses: Não

Contribuição dos autores: $A B M L$ pesquisador principal, elaboração da pesquisa, elaboração do cronograma, levantamento da literatura, coleta e análise dos dados, redação do artigo, submissão e trâmites do artigo; VMNS coautora, elaboração da pesquisa, elaboração do cronograma, levantamento da literatura, coleta e análise dos dados, redação do artigo; $C G O G, F C L$ e $R T$ coautores, coleta de dados, aprovação da versão final.

Endereço para correspondência: Adriana Bendes Moreira de Lacerda. R. Sydnei Antonio Rangel Santos, 238, Santo Inácio, Curitiba (PR), Brasil, CEP: 82010-330. E-mail: adriana.lacerda@utp.br

Recebido em: 6/11/2012; Aceito em: 23/7/2013 


\section{INTRODUÇÃO}

A formação do estilo de vida do adolescente é crucial, não somente para ele, mas também para as gerações futuras. $\mathrm{O}$ Brasil vivencia o chamado bônus demográfico, momento em que a estrutura etária da população atua no sentido de facilitar o crescimento econômico, ou seja, há um grande contingente de população jovem e um menor número de idosos e crianças. O país contava, em 2009, com 34,5 milhões de adolescentes, $92 \%$ deles frequentando escolas ${ }^{(1)}$. Assim, a escola se constitui em um espaço privilegiado para a implementação das políticas públicas, especialmente de educação em saúde, possibilitando, dentre outras ações de saúde, a promoção da saúde auditiva e prevenção da perda auditiva nos adolescentes.

Dentre as ações programáticas direcionadas à promoção da saúde auditiva e à proteção específica de escolares, estão os programas de promoção de saúde auditiva sustentados por três grandes eixos: a análise situacional dos determinantes da saúde auditiva, a análise do perfil audiológico e a intervenção fonoaudiológica voltada para a educação em saúde auditiva ${ }^{(2)}$. Nesse contexto, destaca-se a importância das ações educativas baseadas no comportamento relacionado às atitudes e aos hábitos auditivos de crianças e adolescentes ${ }^{(3)}$. Assim, pode-se atuar mais objetivamente na reflexão sobre a prevenção dos prejuízos decorrentes da exposição ao ruído ambiental e atividades de lazer, visando prevenir, em escolares, a perda auditiva induzida por níveis de pressão sonora elevados (NPSE).

Partindo do pressuposto que um dos componentes mais significativos do desenvolvimento na adolescência compreende a tendência grupal, numa busca de identidade fora do âmbito familiar, onde o jovem tende a sentir-se protegido, seguro, encorajado e compreendido ${ }^{(4)}$, as atividades grupais como método de Educação em Saúde devem ter primazia na faixa etária dos adolescentes ${ }^{(5)}$.

O trabalho em grupo, na forma de oficinas ou outros, possibilita a quebra da tradicional relação vertical que existe entre o profissional da saúde e o sujeito da sua ação, sendo uma estratégia facilitadora da expressão individual e coletiva das necessidades, expectativas e circunstâncias de vida que influenciam a saúde. O espaço grupal mediado pelo diálogo entre profissionais da saúde e os sujeitos ou a comunidade, permite a construção da consciência coletiva e o encontro da reflexão com a ação. O diálogo se impõe como caminho pelo qual os homens ganham significação, enquanto sujeitos, e conquistam o mundo para sua libertação, autonomia e transformação, sendo estas as bases do modelo pedagógico problematizador ${ }^{(5-7)}$.

Esse modelo pedagógico, que teve origem no método educativo de Paulo Freire, tem se destacado como metodologia de ensino e aprendizagem para diferentes grupos populacionais. Seus pressupostos são: o diálogo, a valorização do saber e a realidade de vida do educando, com a oferta de informações significativas que objetivam o empoderamento individual e das comunidades, bem como a participação ativa do educando na busca de soluções para os problemas de saúde ${ }^{(6,7)}$.

Os processos educativos grupais, no modelo problematizador, podem contribuir para o desenvolvimento da autonomia dos adolescentes, na relação e ação com o próprio corpo, além de favorecer a sua autoestima e motivação para ações mais amplas na escola e na comunidade, dentre outras ${ }^{(5-7)}$.

Entretanto, na fonoaudiologia, a pedagogia problematizadora é ainda pouco adotada no processo educativo em Educação em Saúde Auditiva de adolescentes. Nesse contexto, o objetivo do presente estudo foi desenvolver e avaliar oficinas educativas sobre saúde auditiva e exposição a ruídos de adolescentes escolares da rede pública de ensino médio.

\section{MÉTODOS}

Trata-se de um estudo de intervenção, realizado com 91 adolescentes que cursavam o ensino médio em uma escola pública na cidade de Curitiba (PR). Desse total, $41 \%$ eram do gênero feminino e $59 \%$ do gênero masculino, sendo $11 \%$ menores de 15 anos e $89 \%$ com idades entre 15 e 19 anos. Foram incluídos na amostra, os alunos de três turmas do segundo e terceiro anos do ensino médio do período da manhã, que foram convidados e aceitaram participar da oficina educativa sobre saúde auditiva. Os alunos foram subdivididos em dois grupos, devido ao grande número, tendo sido realizadas duas oficinas com o mesmo conteúdo e metodologia.

As oficinas tiveram como objetivo a reflexão em grupo sobre os cuidados com a saúde auditiva e a exposição a ruídos nas atividades de lazer, escolares e ambientais. Cada uma teve duas horas de duração e basearam-se nos pressupostos da pedagogia problematizadora. Foram moderadas por duas docentes fonoaudiólogas e duas docentes enfermeiras, com as seguintes estratégias:

1. Apresentação dos jovens e dos moderadores das oficinas (docentes da graduação em fonoaudiologia e enfermagem da Universidade) e da proposta das oficinas, solicitando a participação ativa dos jovens nas atividades.

2. Dramatização da peça de teatro, elaborada por alunos do Curso de Graduação em Enfermagem, intitulada "No Balanço do Busão", que versa sobre a conversa de dois jovens que estão em um ônibus indo para a escola e que escutam música alta com fone de ouvido (Anexo1).

3. Organização de uma roda de conversa, utilizando a dinâmica da batata quente para motivar um diálogo sobre o tema (cinco tiras com questões colocadas em um saco de pano opaco, que circulava de mão em mão entre os jovens, enquanto uma música tocava. Quando a música era interrompida, o adolescente que estivesse com o saco de pano (batata quente), retirava uma pergunta e tentava responder. Os demais jovens debatiam sobre o tema com o auxílio dos moderadores). As questões geradoras foram as seguintes: Quais as fontes de ruído? Quais os efeitos do ruído no ser humano? A perda auditiva induzida por ruído 
(PAIR) é reversível? Como a perda auditiva induzida por ruído (PAIR) pode afetar a sua vida? O que fazer para evitar e se proteger dos efeitos do ruído?

4. Criação de um mural, na própria escola, sobre saúde auditiva e os riscos do ruído, visando alertar outros escolares que não participaram das oficinas. Para essa atividade, os jovens foram distribuídos em quatro grupos, usando a dinâmica das balas (foram colocadas numa sacola, diferentes tipos de bala, de acordo com o número dos participantes e dos grupos que se pretendia formar. Cada adolescente selecionou uma bala e, em seguida, foi solicitado que se agrupassem conforme o tipo de bala escolhido). Cada grupo elaborou e apresentou um cartaz sobre o tema e, no final da apresentação, os cartazes foram fixados no mural da escola, onde permaneceram até o fim do bimestre.

5. Encerramento: os alunos foram estimulados a cantar o "Funk do Ruído", após distribuição da letra da música, elaborada por adolescentes de uma escola do Estado de Santa Catarina (Anexo 2).

Para avaliação da efetividade dessa intervenção, foram aplicados dois questionários: um questionário denominado "Atitudes dos Jovens Frente ao Ruído", que foi respondido antes e depois das oficinas (foram obtidos 87 questionários válidos para análise; quatro questionários foram excluídos devido a à rasuras ou preenchimento incompleto), e outro questionário denominado "Avaliação das Atividades Educativas Desenvolvidas" (respondido por 91 adolescentes).

O questionário "Atitudes do Jovem Frente ao Ruído" foi adaptado para o português/brasileiro ${ }^{(8)}$ a partir do questionário em inglês, Youth Attitude to Noise Scale (YANS) que, originalmente, foi desenvolvido por pesquisadores internacionais ${ }^{(9)}$. A finalidade desse instrumento é explorar as atitudes do adolescente com relação ao ruído, numa escala que trata dos tipos diferentes de sons comuns no seu ambiente. As questões são medidas seguindo a escala de Likert com cinco graus: 1 - "discordo totalmente"; 2 - "discordo parcialmente"; 3 - "concordo"; 4 - "concordo parcialmente" e 5 - "concordo totalmente". Conta com 19 questões, sendo que as questões $1,3,4,7,12,13,15,18$ e 19 são classificadas com a escala de valores descendente (5-1 concordo totalmente a discordo totalmente) e as demais, em escala ascendente (1-5 discordo totalmente a concordo totalmente).

Posteriormente, conforme proposto na referida metodo$\operatorname{logia} a^{(9)}$, as questões foram distribuídas de acordo com quatro fatores: cultura (F1), ruídos diários (F2), ambientes ruidosos (F3) e ambiente sonoro (F4). As questões do fator "cultura" são aquelas que caracterizam as atitudes dos jovens para o ruído, associadas aos elementos culturais, como por exemplo, frequentar discotecas (questões F1: 1, 4, 9, 10, 12, 15 e 18). As questões do fator "ruídos diários" são aquelas que caracterizam as atitudes dos jovens com relação aos ruídos diários, como por exemplo, o ruído de tráfego (questões F2: 8, 11, 14, 16, 17 e 19). As questões do fator "ambientes ruidosos" são aquelas que caracterizam a habilidade de se concentrar em ambientes ruidosos, como por exemplo, ouvir música enquanto faz tarefas escolares (questões F3: 2, 5 e 13). As questões do fator "ambiente sonoro" são aquelas que caracterizam as atitudes capazes de influenciar o ambiente sonoro, como por exemplo, tornar o ambiente sonoro mais confortável (questões F4: 3, 6 e 7).

Para análise dos resultados, foram calculadas as médias dos escores da escala de Likert, nas respostas antes e após a oficina e para a análise estatística foi utilizado o teste t de Student, com nível de significância de $0,05 \%$.

As respostas às perguntas abertas do segundo questionário, “Avaliação das Atividades Desenvolvidas na Oficina", foram categorizadas, apresentado-se, nos resultados, algumas expressões dos jovens para exemplificar as categorias, ou seja, suas percepções sobre a atividade educativa.

Este estudo obteve aprovação do Comitê de Ética do Hospital do Trabalhador, de Curitiba (PR), sob o número 384/2011 e todos os participantes assinaram o Termo de Consentimento Livre e Esclarecido (TCLE).

\section{RESULTADOS}

Nas questões sobre as atitudes dos adolescentes frente ao ruído, observou-se que, após as oficinas, houve melhora na compreensão sobre os efeitos do ruído em 13 questões (questões: $1,2,3,4,8,9,10,12,13,14,15,18$ e 19). Uma questão permaneceu inalterada (questão 5) e, em 10 questões, o número de indefinidos foi reduzido (questões 1 a 8, 12 e 18) (Tabela 1).

Para a análise dos escores das questões sobre as atitudes dos jovens frente ao ruído, antes e após as oficinas, os escores médios mais próximos de cinco (escores mais altos) representaram atitudes mais positivas para a promoção da saúde auditiva. Os resultados após as oficinas demonstraram que, em 13 questões, ocorreram mudanças positivas na compreensão dos jovens, que passaram a considerar o ruído como algo ruim e danoso à saúde. Foi observada diferença $(\mathrm{p}<0,05)$ nas questões relacionadas aos fatores "cultura" (questão 12) e "ruídos diários" (questões 11, 14 e 19) (Tabela 2).

Nos escores das questões, antes e após a oficina educativa, de acordo com os fatores (cultura, ruídos diários, habilidade de se concentrar em ambientes ruidosos e atitudes que influenciam o ambiente sonoro), foi observada diferença entre as médias do fator "cultura" ( $\mathrm{p}=0,0247)$, que caracterizam mudanças nas atitudes dos jovens em relação ao ruído, associadas aos elementos culturais, sobretudo nas atividades de lazer com música (Tabela 3).

Os resultados sobre a percepção dos adolescentes com relação à atividade educativa em que se utilizou como recurso metodológico uma oficina e como modelo pedagógico a pedagogia problematizadora, apontaram que os alunos consideraram a atividade muito boa ou boa, em mais de $80 \%$ das avaliações, afirmando que a atividade educativa contribuiu para ampliação dos conhecimentos sobre o tema. Os jovens relataram 
Tabela 1. Comparação dos resultados das questõ es sobre as atitudes dos adolescentes frente ao ruído, antes e após as oficinas

\begin{tabular}{|c|c|c|c|c|c|c|c|c|}
\hline \multirow{2}{*}{ Questões } & \multicolumn{2}{|c|}{ Concordo } & \multicolumn{2}{|c|}{ Discordo } & \multicolumn{2}{|c|}{ Indefinido } & \multicolumn{2}{|c|}{ Em branco } \\
\hline & Antes & Após & Antes & Após & Antes & Após & Antes & Após \\
\hline 1. Acho que o volume do som nas discotecas, bailes é alto demais (F1). & 33,3 & $44,5^{*}$ & 60,0 & 48,9 & 6,7 & $3,3^{*}$ & 0,0 & 3,3 \\
\hline 2. Ouvir música enquanto faço tarefa escolar ajuda a me concentrar (F3). & 51,1 & 47,8 & 41,1 & $43,3^{*}$ & 7,8 & $5,6^{*}$ & 0,0 & 3,3 \\
\hline $\begin{array}{l}\text { 3. Estou preparado para fazer algo que torne meu ambiente escolar mais } \\
\text { silencioso (F4). }\end{array}$ & 56,7 & $58,9^{*}$ & 15,6 & 12,2 & 27,8 & $25,6^{*}$ & 0,0 & 3,3 \\
\hline $\begin{array}{l}\text { 4. Quando o nível de som está muito alto, eu considero a possibilidade de sair de } \\
\text { uma discoteca (F1). }\end{array}$ & 26,7 & $37,8^{*}$ & 53,3 & 43,3 & 18,9 & $15,6^{*}$ & 1,1 & 3,3 \\
\hline 5. Consigo me concentrar mesmo se há muitos sons diferentes à minha volta (F3). & 38,9 & 38,9 & $50,0^{*}$ & $50,0^{*}$ & 11,1 & $7,8^{*}$ & 0,0 & 3,3 \\
\hline 6. Acho desnecessário utilizar protetor auditivo quando estou numa discoteca (F4). & 50,0 & 57,8 & 36,7 & 28,9 & 11,1 & $8,9^{*}$ & 2,2 & 4,4 \\
\hline 7. É importante para mim, tornar o som do meu ambiente mais confortável (F4). & 82,2 & 78,9 & 6,7 & 10,0 & 11,1 & $7,8^{*}$ & 0,0 & 3,3 \\
\hline 8. Eu não gosto quando está quieto à minha volta (F2). & 57,8 & 61,1 & 24,5 & $25,6^{*}$ & 17,8 & $8,9^{*}$ & 0,0 & 4,4 \\
\hline 9. O volume do som em discotecas não é um problema (F1). & 64,5 & 60,0 & 26,7 & $27,8^{*}$ & 8,9 & 8,9 & 0,0 & 3,3 \\
\hline 13. Eu acho que a sala de aula deveria ser silenciosa e calma (F3). & 51,1 & $51,2^{*}$ & 33,3 & 27,8 & 15,6 & 15,6 & 0,0 & 4,4 \\
\hline 14. Os sons de ventiladores, geladeiras e etc., não me perturbam (F2). & 66,7 & 50,0 & 23,3 & $28,9^{*}$ & 10,0 & 17,8 & 0,0 & 3,3 \\
\hline $\begin{array}{l}\text { 15. Eu estou preparado para desistir de atividades onde o volume do som é alto } \\
\text { demais (F1). }\end{array}$ & 34,5 & $41,1^{\star}$ & 47,8 & 34,4 & 17,8 & 20,0 & 0,0 & 4,4 \\
\hline 16. O volume do som na minha escola é confortável (F2). & 40,0 & 33,3 & 43,3 & 41,1 & 16,7 & 22,2 & 0,0 & 3,3 \\
\hline 17. Para mim, é fácil ignorar barulho de trânsito (F2). & 40,0 & 44,5 & 53,3 & 41,1 & 6,7 & 11,1 & 0,0 & 3,3 \\
\hline $\begin{array}{l}\text { 18. Deveria haver mais regras ou regulamentos para o volume de sons na } \\
\text { sociedade (F1). }\end{array}$ & 54,4 & 53,3 & 27,8 & $31,1^{*}$ & 17,8 & $11,1^{*}$ & 0,0 & 4,4 \\
\hline 19. Quando não posso me livrar de sons incômodos, eu me sinto desprotegido (F2). & 43,3 & $48,9^{*}$ & 41,1 & 27,8 & 15,6 & 20,0 & 0,0 & 3,3 \\
\hline
\end{tabular}

*Valores significativos $(p<0,05)$ - Teste t de Student

Legenda: F1 = cultura; F2 = ruídos diários; F3 = ambientes ruidosos; F4 = ambiente sonoro

Tabela 2. Comparação dos escores das questões sobre atitudes dos jovens frente ao ruído antes e após a oficina

\begin{tabular}{|c|c|c|c|c|c|}
\hline \multirow{2}{*}{ Questões } & \multicolumn{2}{|c|}{ Média } & \multicolumn{2}{|c|}{ Desvio-padrão } & \multirow{2}{*}{$\begin{array}{l}\text { Valor } \\
\text { de } p\end{array}$} \\
\hline & Antes & Após & Antes & Após & \\
\hline 1. Acho que o volume do som nas discotecas, bailes é alto demais (F1). & 2,74 & 2,89 & 1,25 & 1,51 & 0,3201 \\
\hline 2. Ouvir música enquanto faço tarefa escolar ajuda a me concentrar (F3). & 2,82 & 2,87 & 1,49 & 1,52 & 0,7169 \\
\hline 3. Estou preparado para fazer algo que torne meu ambiente escolar mais silencioso (F4). & 3,57 & 3,63 & 1,05 & 1,04 & 0,5905 \\
\hline 4. Quando o nível de som está muito alto, eu considero a possibilidade de sair de uma discoteca (F1). & . 2,62 & 2,86 & 1,22 & 1,36 & 0,1751 \\
\hline 5. Consigo me concentrar mesmo se há muitos sons diferentes à minha volta (F3). & 3,15 & 3,16 & 1,30 & 1,42 & 0,9552 \\
\hline 6. Acho desnecessário utilizar protetor auditivo quando estou numa discoteca (F4). & 2,83 & 2,50 & 1,35 & 1,33 & 0,1308 \\
\hline 7. É importante para mim, tornar o som do meu ambiente mais confortável (F4). & 4,09 & 4,06 & 0,94 & 1,03 & 0,7868 \\
\hline 8. Eu não gosto quando está quieto à minha volta (F2). & 2,55 & 2,52 & 1,26 & 1,33 & 0,7539 \\
\hline 9. O volume do som em discotecas não é um problema $(\mathrm{F} 1)$. & 2,43 & 2,51 & 1,25 & 1,31 & 0,6113 \\
\hline 10. Barulhos e sons altos são aspectos naturais de nossa sociedade (F1). & 2,20 & 2,45 & 1,17 & 1,24 & 0,2529 \\
\hline 11. O barulho do trânsito não é perturbador (F2). & 3,49 & 2,99 & 1,32 & 1,43 & $0,0065^{*}$ \\
\hline 12. O nível do som deveria ser diminuído em discotecas (F1). & 2,52 & 3,31 & 1,35 & 1,41 & $0,0000^{*}$ \\
\hline 13. Eu acho que a sala de aula deveria ser silenciosa e calma (F3). & 3,28 & 3,36 & 1,36 & 1,37 & 0,5406 \\
\hline 14. Os sons de ventiladores, geladeiras e etc., não me perturbam (F2). & 2,37 & 2,75 & 1,20 & 1,33 & $0,0229^{*}$ \\
\hline 15. Eu estou preparado para desistir de atividades onde o volume do som é alto demais (F1). & 2,75 & 3,10 & 1,22 & 1,29 & 0,0581 \\
\hline 16. O volume do som na minha escola é confortável (F2). & 2,97 & 3,17 & 1,31 & 1,29 & 0,2649 \\
\hline 17. Para mim, é fácil ignorar barulho de trânsito (F2). & 3,11 & 2,90 & 1,34 & 1,36 & 0,1473 \\
\hline 18. Deveria haver mais regras ou regulamentos para o volume de sons na sociedade (F1). & 3,41 & 3,37 & 1,27 & 1,36 & 0,6828 \\
\hline 19. Quando não posso me livrar de sons incômodos, eu me sinto desprotegido (F2). & 3,07 & 3,34 & 1,28 & 1,27 & $0,0464^{*}$ \\
\hline
\end{tabular}

*Valores significativos $(p<0,05)$ - Teste t de Student

Legenda: $F 1=$ cultura; $F 2$ = ruídos diários; F3 = ambientes ruidosos; F4 = ambiente sonoro 
Tabela 3. Comparação dos resultados dos escores das questões, antes e após as oficinas

\begin{tabular}{|c|c|c|c|c|c|c|}
\hline \multirow{2}{*}{ Fatores } & \multirow{2}{*}{$\mathrm{n}$} & \multicolumn{2}{|c|}{ Média } & \multicolumn{2}{|c|}{ Desvio-padrão } & \multirow{2}{*}{ Valor de $p$} \\
\hline & & Antes & Após & Antes & Após & \\
\hline Cultura (F1) & 84 & 3,07 & 3,23 & 0,52 & 0,64 & $0,0247^{*}$ \\
\hline Ruídos diários (F2) & 85 & 3,08 & 3,17 & 0,50 & 0,66 & 0,2348 \\
\hline Ambientes ruidosos (F3) & 86 & 3,10 & 3,09 & 0,72 & 0,84 & 0,9392 \\
\hline Ambientes sonoros (F4) & 84 & 3,62 & 3,71 & 0,72 & 0,67 & 0,3072 \\
\hline
\end{tabular}

*Valores significativos $(p<0,05)$ - Teste t de Student

Nota: Os valores de "n" variaram, pois o teste somente poderia ser aplicado quando todas as questões fossem respondidas. Assim, as questões não respondidas (em branco) foram excluídas desta tabela

Tabela 4. Percepção dos adolescentes sobre a atividade educativa $(\mathrm{n}=91)$

\begin{tabular}{lc}
\hline Variáveis & $\%$ \\
\hline Conceito atribuído & 53,8 \\
Muito bom & 39,7 \\
Bom & 6,4 \\
Regular & \\
O que mais gostou na atividade educativa? & 28,1 \\
Das informações sobre o tema & 25,8 \\
Da Música & 16,9 \\
Do Teatro & 14,6 \\
Das Dinâmicas & 9,0 \\
De Tudo & 5,6 \\
Outras & \\
A oficina contribuiu para ampliar seu conhecimento? & 88,1 \\
$\quad$ Sim & 11,9 \\
\hline Não & \\
\hline Nota: Os percentuais foram calculados sobre o total de respondentes de cada \\
questão
\end{tabular}

ter apreciado as atividades propostas, destacando o que mais gostaram na oficina (Tabela 4).

Para exemplificar as respostas sobre a satisfação dos adolescentes em relação à atividade educativa realizada, categorizadas e apresentadas na Tabela 4, destacamos algumas de suas expressões, como parte dos resultados:

"Ajudou a esclarecer as dúvidas sobre o assunto"

"Informou sobre a prevenção/riscos do ruído"

"Gostei de saber sobre os ruídos em geral e que causam problemas à saúde"

"Eu entendi mais sobre a poluição sonora"

"Gostei da descontração e participação de todos sobre algo que é muito importante"

"Ter abordado esse tema pouco discutido"

"Gostei da iniciativa dos professores da Universidade de vir até a nossa escola"

"Parabéns pelas dinâmicas, por mim conquistaram seus objetivos"

"Aprendi muito, pois gostava de ouvir música alta e com fone de ouvido no último volume"
"Trabalho muito bom que contribuirá para mudança de atitude"

"Gostei bastante, aumentou meus conhecimentos e também a preocupação com a minha saúde, e minhas futuras gerações"

"Podiam vir mais vezes e trazer assuntos diferentes"

\section{DISCUSSÃO}

Estudos demonstram que a perda auditiva entre os adolescentes pode ser ocasionada por fatores condicionantes, como os hábitos e atitudes/comportamentos desenvolvidos por essa população, sendo necessárias ações que propiciem esclarecimentos sobre essa temática. A perda auditiva induzida pelo ruído (PAIR) pode determinar transtornos na vida dos jovens quanto ao aproveitamento escolar, ao convívio social e, futuramente, na vida profissional ${ }^{(8-12)}$.

Nesse contexto, promover a saúde auditiva significa possibilitar melhor qualidade de vida e bem estar às populações atendidas no âmbito da Fonoaudiologia ${ }^{(13-16)}$.

Os resultados deste estudo demonstraram que os adolescentes tinham hábitos e atitudes/comportamentos inadequados, podendo ser nocivos e causar danos à saúde (Tabela 1). Em um comparativo com estudo nacional ${ }^{(8)}$, hábitos e atitudes/comportamentos dos adolescentes avaliados pelos autores apresentaram-se semelhantes aos dos adolescentes do presente estudo.

Segundo autores, o hábito mais comum entre os participantes é ouvir música com dispositivos de escuta pessoal (MP3, MP4 e iPod ${ }^{\circledR}$ ), sendo que as meninas têm atitudes mais negativas para o ruído que os meninos ${ }^{(8)}$. Autores ${ }^{(8,12,17-19)}$ relatam que os conceitos de adolescência e de música alta estão normalmente associados. Escutar música em intensidade elevada é um hábito comum entre os jovens. Os resultados de estudo ${ }^{(12)}$ relacionado às atitudes dos adolescentes frente ao ruído presente em diferentes locais, sugerem que a cultura atual da juventude não parece preocupar-se com os efeitos nocivos dos sons intensos.

No entanto, como na atividade educativa desenvolvida foram observadas mudanças na compreensão dos jovens (Tabelas 1 e 2), que passaram a considerar o ruído como algo ruim e danoso à saúde, pode-se inferir que a falta de informação e de atividades educativas interessantes para os jovens contribua para atitudes inadequadas com relação à saúde auditiva e aos efeitos do ruído. 
Diferenças significativas nas respostas, antes e após as oficinas, foram observadas nos fatores "cultural" e "ruídos diários" (Tabela 2) e nos escores das questões relacionadas ao fator "cultural" (Tabela 3). Esses resultados podem ter ocorrido pela própria dinâmica das oficinas, onde houve maior interesse dos jovens sobre esclarecimentos relacionados às atividades de lazer com música (intensidade sonora das discotecas, shows, dispositivos de escuta pessoal, etc) e aos ruídos diários (incômodos com vizinhos, trânsito, etc).

A percepção dos adolescentes demonstrou que a avaliação das oficinas foi positiva, sendo o método considerado muito bom e bom (Tabela 4). Nesse pressuposto, a proposta da ação educativa com a participação grupal foi baseada nas recomendações do Ministério da Saúde ${ }^{(5)}$, fundamentando que o grupo é um espaço privilegiado para a promoção da saúde e prevenção de agravos. Essa estratégia se coaduna melhor às necessidades da faixa etária dos adolescentes, tais como fazer parte de um grupo, ser ouvido e respeitado. É nesse espaço de atenção, também, que se pode construir uma rede de proteção social que garanta os direitos dessa população ${ }^{(5)}$.

Já a pedagogia problematizadora como método de educação em saúde auditiva foi escolhida por ser um método ativo/reflexivo. Ativo, porque dá oportunidade à expressão do pensamento e das experiências pessoais do grupo; reflexivo, porque para falar de uma realidade, resolver um problema ou defender uma ideia, o grupo precisa analisar, julgar, propor soluções e usar suas capacidades mentais para cuidar da própria saúde ${ }^{(6,7)}$.

Assim, a pedagogia problematizadora tenta superar as limitações do método tradicional ou de transmissão vertical de conhecimento, através de palestras e orientações padronizadas, bem como superar as limitações do método condicionador que dita fórmulas/normas de comportamento ${ }^{(6,7,20-23)}$, sendo os dois últimos, tradicionalmente muito usados na intervenção fonoaudiológica.

A equipe interdisciplinar, mediadora das oficinas, contribuiu de forma importante para o sucesso das ações. A contribuição na área da enfermagem com relação ao método problematizador e a contribuição sobre saúde auditiva na área da fonoaudiologia foram fundamentais para o êxito das oficinas educativas.

Além disso, a participação de alunos do curso de enfermagem no teatro despertou nos adolescentes o interesse pelo tema, influenciando-os na reflexão sobre hábitos mais saudáveis. Os fundamentos da teoria cognitiva social ${ }^{(24)}$ reforçam que comportamentos são aprendidos e adaptados entre as relações interpessoais com os outros e com o ambiente, em um modelo recíproco, em que os sujeitos podem compreender e antecipar resultados de um comportamento prescrito. Nessa perspectiva, são recomendadas ações voltadas à promoção e prevenção protagonizadas por jovens saudáveis e com um estilo de vida adequado, capaz de influenciar outros jovens ${ }^{(25)}$.

A fala dos adolescentes entrevistados sobre a percepção da dinâmica das oficinas demonstrou aprovação e apreciação das atividades propostas. Para autores ${ }^{(26-29)}$, a educação em saúde no trabalho com adolescentes deve compreender o desenvolvimento de ações que democratizem o acesso às informações. Tal acesso é necessário à efetivação do alcance à saúde e demais direitos sociais são ações que devem contribuir para a formação de consciência crítica e incentivar o exercício do controle social, o desenvolvimento da solidariedade e da justiça, aspectos convergentes entre saúde e educação.

Embora esta ação educativa tenha sido realizada em duas oficinas, sendo portanto, um possível fator limitador do estudo, os resultados obtidos apontaram que houve transformação, pois os escolares assumiram um posicionamento que não tinham antes e reelaboraram seus conhecimentos usando formas diferentes de falar. Demonstraram atitudes de apoio e afeto uns com os outros, e afirmaram que adquiriram novos conhecimentos sobre os efeitos do ruído. Recomenda-se que esse modelo de intervenção seja reproduzido em outras escolas e revalidado em outros estudos.

Ressalta-se que o programa de promoção de saúde e prevenção da perda auditiva continuou durante todo o ano letivo na escola, com a análise situacional dos determinantes de saúde e análise do perfil audiológico dos escolares. Outra etapa desenvolvida na escola foi a do protagonismo juvenil em saúde ${ }^{(30)}$, estimulando e formando os jovens agentes de saúde auditiva a dar continuidade às ações educativas na escola.

Nesse contexto, encorajamos os fonoaudiólogos e outros profissionais a desenvolver programas que objetivem a promoção e proteção da saúde nas escolas e a usar como estratégia a pedagogia problematizadora nas oficinas educativas. Sugerimos que a saúde auditiva e a qualidade de vida estejam no foco da promoção da saúde dos adolescentes.

O setor educacional, por sua capilaridade e abrangência, é um aliado importante para a concretização de ações de promoção da saúde voltadas ao fortalecimento das capacidades dos indivíduos, a tomada de decisões favoráveis à sua saúde e à saúde da comunidade. Permite a criação de ambientes saudáveis e a consolidação de uma política intersetorial voltada à qualidade de vida, pautada no respeito ao indivíduo e tendo como foco a construção de uma nova cultura da saúde.

Para uma atuação mais eficiente, existe a necessidade de se formar profissionais com a visão da promoção da saúde e da pedagogia problematizadora, para que possam contribuir de forma mais efetiva para a melhoria da qualidade de vida dos adolescentes e na sua formação como cidadãos.

\section{CONCLUSÃO}

Foram observadas mudanças na compreensão dos jovens, sobretudo quanto aos efeitos do ruído nas atividades culturais. As estratégias lúdicas e dialógicas propostas nas oficinas foram aceitas e apreciadas pelos adolescentes. As oficinas educativas propostas são apropriadas para educação em saúde auditiva de escolares. 


\section{REFERÊNCIAS}

1. Brasil. Instituto Brasileiro de Geografia e Estatística. Pesquisa Nacional de Saúde do Escolar (PeNSE) 2009. Rio de Janeiro: IBGE; 2009. [Internet]. [acesso em: $2011 \mathrm{dez}$. Disponível em: http://www. ibge.gov.br/home/estatistica/populacao/pense/

2. Lacerda ABM. Audição no contexto escolar: práticas voltadas à promoção e à prevenção. In: Bevilacqua M, Balen P, Reis F. (Org.). Tratado de Audiologia. São Paulo: Santos; 2011. p 549-70.

3. Morata TC. Young people: their noise and music exposures and the risk of hearing loss. Int J Audiol. 2007;46(3):111-2.

4. Araújo A, Rocha RL, Armond LC. Da tendência grupal aos grupos operativos com adolescentes: a identificação dos pares facilitando o processo de orientação e educação em saúde. Revista Médica de Minas Gerais. 2008;18(4-S1):123-30.

5. Brasil. Ministério da Saúde. Secretaria de Atenção em Saúde. Departamento de Ações Programáticas Estratégicas. Área Técnica de Saúde do Adolescente e do Jovem. Diretrizes nacionais para a atenção integral à saúde de adolescentes e jovens na promoção, proteção e recuperação da saúde. Série A. Normas e Manuais Técnicos. Brasília: Ministério da Saúde; 2010.

6. Kruschewsky JE, Kruschewsky ME, Cardoso JP. Experiências pedagógicas de educação popular em saúde: a pedagogia tradicional versus a problematizadora, um estudo de revisão. Rev Saúde Com. 2008Jul/Dez;4(2):160-76.

7. Alvim NAT, Ferreira MA. Perspectiva problematizadora da educação popular em saúde e a enfermagem. Texto Contexto Enferm. Florianópolis. 2007Abr-Jun;16(2):315-19.

8. Zocoli AMF, Morata TC, Marques JM. Adaptação para o português brasileiro do questionário Youth Attitude to Noise Scale (YANS). Rev Bras Otorrinolaringol. 2009;75(4):485-92.

9. Olsen SE. Psychological aspects of adolescents' perceptions and habits in noisy environments [tese]. Sweden: Departament of Psycology - Göteborg University; 2004.

10. Serra MR, Biassoni EC, Richter U, Minoldo G, Franco G, Abraham $\mathrm{S}$, et al. Recreational noise exposure and effects on the hearing of adolescents. Part I: An interdisciplinary long-termstudy. Int J Audiol. 2005Feb;44(2):65-73.

11. Serra MR, Biassoni EC, Hinalaf M, Pavlik M, Villalobo JP, Curet C et al. Program for the conservation and promotion of hearing among adolescents. Am J Audiol. 2007Dec:16(2):158-64.

12. Lacerda ABM, Gonçalves CGO, Zocoli A, Dias C, Paula K. Hábitos auditivos e comportamento de adolescentes diante das atividades de lazer ruidosas. Rev CEFAC. 2011;13(2):322-9.

13. Penteado RZ, Servilha EAM. Fonoaudióloga em saúde publica/ coletiva: compreendendo a prevenção e o paradigma da promoção da saúde. Distúrb Comun. 2004;16(1):107-16.

14. Lipay MS, Almeida EC. A fonoaudiologia e sua inserção na saúde pública. Rev Ciênc Méd. 2007Jan-Fev;16(1):31-41.
15. Almeida SMVT, Reis RA. Políticas públicas de saúde em fonoaudiologia. In: Fernandes FDM, Mendes BCA, Navas ALPGP (Orgs.). Tratado de fonoaudiologia. 2a. ed. São Paulo: Roca; 2009. p.640-55.

16. Chum RYS. Promoção da saúde e a produção do cuidado em fonoaudiologia. In: Fernandes FDM, Mendes BCA, Navas ALPGP (Orgs.). Tratado de Fonoaudiologia. 2a.ed. São Paulo: Roca; 2009. p. $605-11$.

17. Soares VNM, Lacerda ABM, Lopes FC, Testoni RI. Perfil de saúde, comportamentos e hábitos auditivos de escolares em Curitiba. Tuiuti: Ciência e Cultura, Curitiba. 2013;46:137-49.

18. Samelli AG, Schochat E. Perda auditiva induzida por nível de pressão sonora elevado em um grupo de músicos profissionais de rock-androll. Acta AWHO. 2000Jul-Set;19(3):136-43.

19. Luz TS, Borja ALVF. Sintomas auditivos em usuários de estéreos pessoais. Int Arch Otorhinolaryngol. 2012;16(2):163-9.

20. Bordenave JED. Alguns fatores pedagógicos. Revista Interamericana de Educação de Adultos. 1983;(3):1-2.

21. Ferreira MA. Educação na adolescência: grupo de discussão como estratégia de pesquisa e cuidado-educação. Texto \& contexto enferm. 2006Abr-Jun;15(2):205-11.

22. Campos JDB, Zuanon ACC. Educação em saúde: aspectos relevantes apontados por adolescentes. Ciênc Odontol Braz. 2004AbrJun;7(2):55-60.

23. Souza AC, Colomé ICS, Costa LED, Oliveira DLLC. A educação em saúde com grupos na comunidade: uma estratégia facilitadora da promoção da saúde. Rev Gaúcha Enferm. 2005Ago;26(2):147-53.

24. Bandura A. Social foundations of thought and action: a social cognitive theory. Engle Wood Cliffs: Prentice Hall. 1986

25. Sobel J, Meikle M. Applying health behavior theory to hearingconservation interventions. Semin Hear. 2008;29(1):81-9.

26. Camargo M. Oficina de educação em saúde com adolescentes: relações de trocas interindividuais no contexto das interações. Cadernos de Aplicação. 2008;21(2):571-79.

27. Horta NC, Sena RR. Abordagem ao adolescente e ao jovem nas políticas públicas de saúde no Brasil: um estudo de revisão. Physis. 2010;20(2):475-95.

28. Horta NC, Lage AMD, Sena RR. Produção científica sobre políticas públicas direcionadas para jovens. Rev Enferm UERJ. 2009;17(4):538-43.

29. Santos AAG, Silva RM, Machado MFAS, Vieira LJES, Catrib AMFJ, Herla MF. Sentidos atribuídos por profissionais à promoção da saúde do adolescente. Cien Saude Colet. 2012;17(5):1275-84.

30. Soares VNM, Lacerda ABM. Atividades grupais e o protagonismo juvenil em saúde do escolar no âmbito da fonoaudiologia. In: Berberian AP, Santana AP (Orgs.) Fonaudiologia em contextos grupais: referenciais teóricos e práticos. Curitiba: Plexus; 2012. p.183-201. 
Anexo 1. Peça de teatro sobre os riscos do ruído

(Narrador) Vocês vão assistir agora a dramatização da peça: "No balanço do busão"

(Narrador): João Victor pega o ônibus Inter II em Curitiba, e encontra o amigo Carlos.

(João Victor falando alto, tenta conversar com Carlos que já tem perda auditiva pq está sempre escutando música alta no celular com fones de ouvido, estava curtindo uma música, dando de ombros como se estivessem dançando.

1. João Victor: E aí Carlão, tudo bem? (batendo as mãos em cumprimento jovial)

1. Carlos: Beleza.

2. João Victor: É, essa semana vai ter casamento na realeza (Londres)

2. Carlos: Do que você ta falando, meu?

3. João Victor: Também curto a natureza.

3. Carlos: (fica olhando para o amigo, como que esperando algum comentário, por não ouvir que o amigo disse) (trocam uns sinais de positivo e expressões faciais)

4. João Victor: E então, ainda tá namorando a Jenifer Jussara?

4. Carlos: Tô,e ela tem os mais belos pares de pernas que já vi.

5. João Victor: Você passeia com ela para ver bem-te-vi? É melhor ir ao cinema, coisa e tal.

\section{PASSAGEIRO: RECLAMA DO SOM ALTO}

\section{MOTORISTA: FREIADA - SAI DA FRENTE CACHORRO}

5. Carlos: Éh... Jenifer Jussara é muito especial, ela me escuta sempre é mais que namora é amiga.

6. João Victor: Pô, deixa de briga? Fica com ela, é mó legal essa mina,

6. Carlos: Não dá para conversar com você cara, acho que você ta louco.

7. João Victor: É falta pouco.

7. Carlos: João Victor, você ta escutando o que eu falo?

8. João Victor: Só, (acena com a cabeça), vai jogar seu namoro no ralo?
8. Carlos: Não falei nada disso, falei que você ta ficando surdo.

9. João Victor: O quê que é um absurdo? Não entendi direito. PASSAGEIRO: RECLAMANDO DO SOM ALTO MOTORISTA: AI! UMA LOMBADA

9. Carlos: Falei que você tá surdo. Não escuta nada que a gente fala. 10. João Victor Ah! Se ela baba, é realmente um absurdo, assim não dá nem para sair com ela.

10. Carlos: Eu te disse que você ta surdo, não falei nada disso.

11. João Victor: É se for simpatia, pode curar com feitiço.

11. Carlos: (veemente, já perdendo a paciência) Pô cara, ta impossível conversar com você, tá surdo como um porta.

12. João Victor: Gorda como uma porca? Faz ela parar de comer, entrar numa academia, então.

12. Carlos: (agora já estourando com o amigo, retira o fone do amigo) Cara, presta atenção, não falei nada disso (falando com calma, articulando bem as palavras, para que o amigo faça leitura labial). Falei que você ta surdo.

13. João Victor: Qual é cara, vai ficar falando de absurdo até quando, muda o disco, ouve uma música que te acalma, de preferência num volume bem alto, que chega até a vibrar o coração.

13. Carlos: Rapá, vou te falar uma coisa séria, se você não tomar cuidado, o pouco de audição que tem vai pro brejo.

14. João Victor: Concordo, o que mais gosto do namoro é o beijo.

14. Carlos: Assim não dá cara, desde que você passou a ouvir o RESTART no MP3 por duas horas todos os dias com esse som ultramega-hiper-potente, não é mais possível ter um diálogo com você.

(Sai sem cumprimentar o amigo, gesticulando)

15. João Victor: (virando para o público) Tem gente que não sabe curtir as coisas boas da vida. Mas... será???? acho que perdi mais um amigo????? Vou descer.... sai da frente galera!!!!! (vira, saindo de cena)

Anexo 2. Música sobre o ruído-ritmo Funk

\begin{tabular}{|ll}
\hline Funk do ruído & Mas se vocês não sabem como \\
Eu sou o MC João & Nós iremos lhe ensinar \\
Venho dizer pra vocês & Abaixe o volume do som \\
Uma coisa importante & Quando você for escutar \\
Que todos devem saber & Refrão: Ido iido é o funk do ruído, Ido iiido é o funk do ruído \\
O assunto é o ruído & E o ruído não escolhe \\
O que nos faz tanto mal & Nem pessoa e nem idade \\
Pode crer, tenha certeza & Toda dia, toda hora \\
Pois já não escuto igual & Toma nossa liberdade \\
Refrão: Ido iido é o funk do ruído, ido iido é o funk do ruído & Mas nós temos o direito \\
É nos fizemos esse funk & De com isso acabar \\
Pra você se conscientizar & Basta que o protetor \\
Que a saúde dos ouvidos & Todos comecem a usar. \\
Também devemos cuidar & Refrão: Ido iido é o funk do ruído, Ido iiido é o funk do ruído
\end{tabular}

